九州大学学術情報リポジトリ

Kyushu University Institutional Repository

\title{
Impact of Land Fragmentation on Economic Feasibility of Farmers in Rice-Based Farming System in Myanmar
}

Lon, Yin

Laboratory of Farm Management, Division of Agricultural and Resource Economics, Department of Agricultural and Resource Economics, Graduate School of Bioresource and Bioenvironmental Sciences, Kyushu University

Hotta, Kazuhiko

Faculty of Agriculture, Kyushu University

Nanseki, Teruaki

Faculty of Agriculture, Kyushu University

https://doi.org/10.5109/19545

出版情報 : 九州大学大学院農学研究院紀要. 56 (1)，pp. 163-170, 2011-02. 九州大学大学院農学研究院 バージョン：

権利関係: 


\title{
Impact of Land Fragmentation on Economic Feasibility of Farmers in Rice-Based Farming System in Myanmar
}

\author{
Yin LON ${ }^{1}$, Kazuhiko HOTTA ${ }^{2}$ and Teruaki NANSEKI ${ }^{2 *}$
}

\author{
Laboratory of Farm Management, Division of Agricultural and Resource Economics, Department of \\ Agricultural and Resource Economics, Graduate School of Bioresource and \\ Bioenvironmental Sciences, Faculty of Agriculture, \\ Kyushu University, 812-8581, Japan \\ (Received November 1, 2010 and accepted November 8, 2010)
}

\begin{abstract}
Land fragmentation, where a single farm has a number of parcels of land, is one of the important features of agriculture in many countries especially in developing countries. This study analyzes the impact of land fragmentation on rice productivity and profitability of rice farmers in Myanmar using farm level survey data. Necessary information was obtained through a farm household survey using questionnaire covering of 143 farms representing different degrees of land fragmentation. Descriptive analysis indicates that farms with low degree of fragmentation obtained higher average rice yield and higher profit margin than those of medium and high degree of fragmentation. The result estimated from Cobb-Douglas frontier production function clearly reveals that land fragmentation has a significant negative effect on rice productivity. The estimated coefficient of land fragmentation is -0.21 implying that $1 \%$ increase in the number of plots, output will be reduced by $0.21 \%$. This might be the result the fragmented land plots that may have a farm structure preventing application of inputs to evenly to all plots of land and discourages farmers from efficient use of land. Farms having many tiny plots lost space along plots boundaries which is directly related to the number of plots that lead to yield decrease. Moreover, unsecure scattering plots may cause yield loss because field plots are scattered over a wide area. Policy recommendation such as addressing structural causes of land fragmentation, providing tradable land use rights, reducing the number plots, and developing rural infrastructure and creating non-farm employment opportunities to release pressure on land are needed to reduce land fragmentation and enhance socio-economic status of farm households.
\end{abstract}

\section{INTRODUCTION}

Land fragmentation where a single farm has a number of parcels of land, is one of the important features of agriculture in many countries, especially in developing countries (Hung et al., 2007). Myanmar is still predominantly an agricultural country with abundant agricultural land. Most of the agricultural land, which is about 7.9 million hectares (19.49 million acres), is currently cultivated by small-scale farmers. The average farm size is 2.3 hectares (5.62 acres) for a country level. Three crop groups: cereal, oil-seed crops and pulses dominate agronomic activity in Myanmar. Rice is the single most important crop (37 percent of total crop production in 2007-2008) and it dominates the agriculture sector which is the largest part of the economy. Any changes in rice production have a direct and profound influence on the entire population. The land area suitable for rice cultivation is 8.1 million hectare (19.9 million acres), about 61 percent of the country's net sown area. According to agricultural census 1993, there were 2.7 million landholdings ${ }^{1}$ comprising over 6.1 million plots of land. The average farm size was 2.35 hectares (5.8 acres) with the average number of plots 2.2 per holding. The average farm size

\footnotetext{
${ }^{1}$ Laboratory of Farm Management, Division of Agricultural and Resource Economics, Department of Agricultural and Resource Economics, Graduate School of Bioresource and Bioenvironmental Sciences, Kyushu University

Faculty of Agriculture, Kyushu University

* Corresponding author (E-mail: nanseki@agr.kyushu-u.ac.jp)
}

slightly increased to 2.52 hectares (6.2 acres) in 2003 agricultural census (the most recent conducted).

Land tenure ${ }^{2}$ was reformed and landlord system was eliminated in 1964. The land use policy was stated in the Land Nationalization Act 1953, Tenancy Act and Rules 1963, and Procedures Conferring the Rights to Cultivate Land 1963. Under this policy, land belongs to the State but farmers are given land use or tillage rights on their holdings, which cannot be transferred, mortgage or taken lieu of loan repayments. However, land right is legally inheritable by family members who remain as farmers and till the land by themselves (FAO/WFP, 2009). The land policy in Myanmar is observed to be rigid, and the land use system is oftentimes irrational and inefficient. These two factors, instead of serving incentives, actually served as disincentives to undertake land improvement activities. Consequently negative development such as land fragmentation and degradation, and deteriorating land productivity, have taken place (Soe, 2004).

Increases in agricultural production can be achieved either by area expansion or by a rise in crop yields per unit area of land. According to UNDP, rice area and production are targeted to increase by $21.4 \%$ and $83.4 \%$ respectively over 15 years from 2001 to 2015 . This presupposes major improvement in productivity, with average yields increasing from about $3300 \mathrm{~kg} / \mathrm{ha}$ to $4851 \mathrm{~kg} /$ ha, a $45 \%$ increase. At the same time the government has been pursuing a policy of allocation of large areas to private sector for agricultural production mainly of rice. Although official statistics indicate significant gains were achieved in rice productivity as a result of these efforts, 
there were few incentives for such increased productivity with no motivation to invest in land improvement (UNDP, 2004). Increasing productivity in agriculture is an effective driver of economic growth and poverty reduction both within and outside agriculture sectors. The matter of how to increase productivity to meet the average target yield and to maintain sustainable agricultural development in the future has become a challenge. One of the important obstacles in this respect may be the higher degree of land fragmentation. Therefore, the impact of land fragmentation on rice production should be considered to improve productivity and farm households' well-being.

This study focuses on monsoon season irrigated rice farmers in Yamethin Township, Mandalay Division. Yamethin Township was selected for this study as it is not only rice growing area but also an area with higher degree of land fragmentation. The objectives of the study are: to assess and compare socio-economic characteristics, rice yield and profitability of farm households under different land fragmentation levels; and to estimate the effects of land fragmentation on rice productivity.

The rest of this paper proceeds with a discussion on the impacts of land fragmentation on agricultural development based on theoretical and empirical studies. The description of the study area and research methodology used to estimate the effects of land fragmentation are provided and the results are discussed. Conclusions are drawn in the final part of this paper.

\section{LAND FRAGMENTATION AND AGRICULTURAL DEVELOPMENT}

Land fragmentation is often believed to be one of the major problems existing in rural management especially in developing countries (Wan and Cheng, 2001). In developing countries, land fragmentation is frequently linked to inheritance customs (Jabarin and Epplin, 1994; Ram et al., 1999; Niroula and Thapa, 2005). Any change in landholding or parcel size invariably influences land use, land productivity, return to inputs and, above all, the status of land. Generally, large farm size has been considered to be necessary for attaining the economies of scale - an essential condition for agricultural commercialization and production promotion (Niroula and Thapa, 2007). However, Schultz (1964) found small farms in developing countries achieve higher production than large farms by using input resources more efficiently (1964 cited in Niroula and Thapa, 2007). This is because small farmers use land more efficiently by the power of their family members and mutually exchanged labor. However, inverse relationship between landholding size and productivity has been weakened due to size-neutral bio- technology and differences in management input (Ram et al., 1999).

Niroula and Thapa (2005) argue that the theory of inverse relationship between farm size and productivity holds little value when the impact of fragmentation of land parcels comprising that holding is considered. Because of the inheritance custom of dividing parental landholdings among household heirs, land parcels of different quality are equally divided among the eligible heirs when they decide to live separately. This leads not only to reduced farm size, but also reduced size and increased the dispersion of parcels over a wide area. Fragmented land parcels can hinder agricultural development in several ways, when each small landholding is further fragmented into numerous small parcels scattered over a wide area with different distance from homestead. Increasing Labor cost due to travelling time from parcel to parcel weakens economic competitiveness of farmers which could lead to reduced net income. Reduced net income and soil fertility are symptoms of land degradation (Niroula and Thapa, 2005). Moreover, land fragmentation has a detrimental effect to farm profitability. This is probably due to inherent inefficiencies arising from the dispersion of land parcels. Fragmented fields are difficult to cultivate, to use farm machineries; loss space along field boundaries; and there are problems with development and management in irrigation systems (Di Falco et al., 2009).

However, fragmented land with different biophysical conditions allow farmers to reduce risks such as drought, flood, fire, diversify crop mixtures and ease seasonal labor bottlenecks (Blarel et al., 1992; Tan et al., 2008). Land fragmentation also allows farmers to grow a wide range of crops with different ripening time so as they may concentrate their labor at different plots at different time, thereby avoiding the period of labor intension and household labor bottlenecks (Todorova and Lulcheva, 2005).

\section{STUDY AREA}

Yamethin is located in Yamethin Districts, Mandalay Division. It lies on Yangon - Mandalay highway road and about 78 kilometers north of Nay Pyi Taw and about 62 kilometers south of Meiktila. It is composed of 68 village tracts $^{3}$ (including 5 wards in Yamethin) and 241 villages with total population about 311,067. Yamethin Township has a total land area of 535,626 acres (1ha=2.47 acres) in which agricultural land accounts for $34.8 \%$ and reserved forest, other forest, cultivable and uncultivable waste land cover $65.2 \%$. Paddy land (Le) and upland (Ya) share the largest part of agricultural land with $44.5 \%$ and $54.8 \%$ respectively. The cultivable waste land, which can be use for land expansion, is 9371 acres (1.9\% of total land

\footnotetext{
An agricultural landholding is the economic unit of agricultural production under single management, comprising all livestock kept and all land used wholly or partly for agricultural production purposes, regardless to title, legal form or size.

Tenure refers to the relationship between the agricultural holder and land he operates concerning his possibilities to use and control this land.

A 'village tract' is typically composed of 3-7 villages; although it is an administrative unit, residents of constituent villages share a common sense of identity to the village tract.
} 
area). Agriculture is the primary economical source of livelihood. Primary crops grown are mainly rice, other crops such as green gram, pigeon pea, sesame, groundnut, sunflower, chilly, maize, fodder crops, and vegetables.

\section{METHODOLOGY}

\section{Model specification of stochastic frontier produc- tion}

The stochastic frontier production function, which was independently proposed by Aigner, Lovell and Schmidt (1977) and Meeusen and van den Broeck (1977), has been a significant contribution to the econometric modeling of production and the estimation of technical efficiency of firms. The original specification for cross-sectional data had an error term which has two components: one to account for random effects and another to account for technical inefficiency. The basic model for cross-sectional data can be expressed as:

$$
\begin{aligned}
\mathrm{Y}_{\mathrm{i}} & =\mathrm{f}\left(\mathrm{x}_{\mathrm{i}}, \beta_{\mathrm{i}}\right)+\varepsilon_{\mathrm{i}}, \mathrm{i}=1, \ldots \ldots \ldots, \mathrm{N} \\
\text { Where, } & \\
\mathrm{N} & =\text { the number of household farm } \\
\mathrm{Y}_{\mathrm{i}} & =\text { the production of the } \mathrm{i}^{\text {th }} \text { farm } \\
\mathrm{X}_{\mathrm{i}} & =\text { a }(\mathrm{k} \times 1) \text { vector of input quantities of the } \mathrm{i}^{\text {th }} \text { farm } \\
\beta & =\text { vector of unknown parameters } \\
\varepsilon & =\text { a composed error term, which can be decom- } \\
& \text { posed as } \\
\varepsilon & =\mathrm{V}_{\mathrm{i}}-\mathrm{U}_{\mathrm{i}}
\end{aligned}
$$

The major feature of stochastic production frontier is that the disturbance term is a composite error consisting of two components, one symmetric and the other one-sided. The symmetric component, $\mathrm{V}_{\mathrm{i}}$, captures the random effects due to measurement error, statistical noise and other influences outside the control of the firm and it is assumed to be normally distributed. The onesided component, $\mathrm{U}_{\mathrm{i}}$, captures randomness under the control of the firm. It gives the derivation from the frontier attributed to inefficiency. It is assumed to be halfnormal distributed.

The half-normal stochastic frontier model is estimated in terms of the variance parameters, $\sigma_{\mathrm{s}}{ }^{2}=\sigma_{\mathrm{u}}{ }^{2}+$ $\sigma_{\mathrm{v}}^{2}$, and $\gamma=\sigma_{\mathrm{u}}{ }^{2} /\left(\sigma_{\mathrm{u}}^{2}+\sigma_{\mathrm{v}}^{2}\right)$. The parameter, $\gamma$, has a value between zero and one. If $\gamma=0$, there are no technical inefficiency effects and all deviations from the frontier are due to noise. This indicate that $\sigma_{u}^{2}$ is zero and hence, the one-sided component, Ui, should be removed from the model, leaving a specification with parameters that can be consistently estimated using average production function (Ordinary Least Squares).

\section{Data}

Primary data for this study was obtained through a farm household survey conducted in Yamethin Township during September - October 2009. Yamethin Township was chosen as a representative region to analyze the impact of land fragmentation. It is composed of 68 village tracts and 241 villages. Four villages where irrigation is available for rice production were randomly selected among 241 villages. Sample households were collected from 4 villages in 4 village tracts with the help of the staffs of Settlement and Land Records Office. Detailed information about rice production, farm characteristics and socio-economic characteristics for monsoon season irrigated rice farmers for 2008 was collected by using the structured questionnaire. A total of 143 farm households with varying plots number were selected and their holdings were classified as low, medium and high degree of fragmentation. Farms consists of plots number between 1-10 are considered to be low, 11-20 plots medium (moderate) and over 20 plots high degree of fragmentation. Holdings fall in the first category are 52 percent, the second accounts for 28 percent and the third accounts for 20 percent of the total sampled holdings.

Total rice output was used as a dependent variable and total land cultivated area, draft animal power, seed, labor, fertilizer were used as independent variables. The effect of land fragmentation is captured by specifying the number of plots per farm as an independent variable in the stochastic production function. All inputs used in Cobb-Douglas frontier production function are expected to have a positive impact on rice output. Land fragmentation indicator, the number of plots can be expected to have a positive or negative impact on rice output.

In Cobb-Douglas frontier production function, land fragmentation affects the entire production process rather than a particular input or particular phase of production. It should be noted that land fragmentation is not an input itself. This variable enters the production system through its possible impacts on productive efficiency (Wan and Cheng, 2001).

Choosing indicators to measure land fragmentation is important. Because there is no standard of measurement of land fragmentation, it is difficult to determine when farm households are 'very fragmented' or 'less fragmented' (Bentley, 1987). In previous studies, many researchers have used single indicators (number of plots, plot size) and integrated indicator (Simpson Index). In this study, number of plots is used as an indicator of land fragmentation. Moreover, using number of plots as an indicator of land fragmentation also facilitates interpretation of estimation results and drawing policy recommendation.

\section{Empirical model}

In this study, we used Cobb-Douglas production function because of it is easy to estimate and interpret, and it requires a few parameters. Moreover, the parameters estimated from this function have provided results which seem to be meaningful from the point of view of economic theory. The Cobb-Douglas frontier production function that will be estimated can be expressed as:

$$
\begin{aligned}
\ln \left(Y_{i}\right)=\beta_{0}+\beta_{1} \ln \left(X_{i 1}\right) & +\beta_{2} \ln \left(X_{i 2}\right)+ \\
& \ldots \ldots \ldots . . \beta_{7} \ln \left(X_{i 7}\right)+\left(V_{i}-U_{i}\right)
\end{aligned}
$$

Where

ln = natural logarithm

$\mathrm{Y}_{\mathrm{i}}=$ Total rice output of the $\mathrm{i}^{\text {th }}$ farm

$\beta_{0}=$ Constant term

$\mathrm{X}_{1}=$ total land cultivated of the $\mathrm{i}^{\text {th }}$ farm 
$\mathrm{X}_{2}=$ animal power used of the $\mathrm{i}^{\text {th }}$ farm

$\mathrm{X}_{3}=$ amount of seed used of the $\mathrm{i}^{\text {th }}$ farm

$\mathrm{X}_{4}=$ labor used of the $\mathrm{i}^{\text {th }}$ farm

$\mathrm{X}_{5}=$ fertilizer (urea) used of the $\mathrm{i}^{\text {th }}$ farm

$\mathrm{X}_{6}=$ farm yard manure (FYM) used of the $\mathrm{i}^{\text {th }}$ farm

$\mathrm{X}_{7}=$ Total number of plots cultivated of the $\mathrm{i}^{\text {th }}$ farm

$\mathrm{V}_{\mathrm{i}}=$ two-sided random variables which accounts for stochastic effects and are assumed to be independently and identically distributed (iid.) as $\mathrm{N}\left(0, \sigma \mathrm{v}^{2}\right)$, and independent of $\mathrm{U}_{\mathrm{i}}$;

$\mathrm{U}_{\mathrm{i}}=$ one-sided non-negative random variables which are assumed to account for technical inefficiency and are assumed to be independently and identically distributed (iid.) as truncations at zero of the $\left|\mathrm{N}\left(\mu, \sigma \mathrm{U}^{2}\right)\right|$ distribution.

The Maximum Likelihood Estimation (MLE) procedure was used to estimate the parameters of the stochastic production frontier by using FRONTIER 4.1 computer program written by T. J. Coelli (1996).

\section{RESULTS}

Socio-economic characteristics of farm households

The socio-economic characteristics of farm households under three levels of land fragmentation groups are presented in Table (1). Groups are classified as low, medium and high degree of fragmentation according to the number of plots they cultivated. Fifty two percent of total households (74 households) fall in low, 28\% (40 households) fall in medium and $20 \%$ of total households (29 households) fall high categories respectively. Age of household heads range from 25 to 77 for overall sampled farmers. The average age of household heads are 52, 53 and 52 years for low, medium and high degree of fragmentation.

The average family members per household are 5, 6 and 7 persons for low, medium and high degree of fragmentation groups respectively. The education level of household heads is fairly low. There are no sampled household heads with college or university education level. Most household heads in three levels of fragmentation have primary and middle school (secondary school) education level. Sixteen percent of household heads for low, $10 \%$ for medium, and $24 \%$ for high degree of fragmentation groups are illiterate. There are more illiterate household heads in high degree of fragmentation than those of low and medium degree of fragmentation. The average schooling years of household heads are 5.2, 6.1 and 5.3 for low, medium and high degree of fragmentation groups respectively.

Farm assets of households in Table (1) show that $5 \%$ of farmers in low degree of fragmentation group do not possess hand tools for use in land preparation, $9 \%$ do not have draft animal power, and 32\% do not own bullock cart as a mean of transportation from house to farm. Because most farmers in this group are small-scale farmers (under 5 acres) and their lands are marginal. Farmers in medium degree of fragmentation group possess all

Table 1. Socioeconomic characteristics of farm households

\begin{tabular}{|c|c|c|c|c|c|}
\hline \multirow[b]{2}{*}{ Characteristics } & \multirow[b]{2}{*}{ Unit } & \multirow[b]{2}{*}{ Category } & \multicolumn{3}{|c|}{ Degree of fragmentation } \\
\hline & & & $\begin{array}{c}\text { Low } \\
(\mathrm{n}=74)\end{array}$ & $\begin{array}{c}\text { Medium } \\
(\mathrm{n}=40)\end{array}$ & $\begin{array}{c}\text { High } \\
(\mathrm{n}=29)\end{array}$ \\
\hline Age of household head & Year & & 52 & 53 & 52 \\
\hline Family size & Number of persons & & 5 & 6 & 7 \\
\hline \multirow{4}{*}{$\begin{array}{l}\text { Education of household } \\
\text { head }\end{array}$} & \multirow{4}{*}{$\%$ of household head } & Illiterate & 16 & 10 & 24 \\
\hline & & Primary & 53 & 40 & 41 \\
\hline & & Middle & 22 & 40 & 21 \\
\hline & & High & 9 & 10 & 14 \\
\hline Schooling year & Year & & 5.2 & 6.1 & 5.3 \\
\hline \multirow{12}{*}{ Farm assets } & \multirow{12}{*}{$\%$ of household head } & Plough & 95 & 100 & 100 \\
\hline & & Harrow & 95 & 100 & 100 \\
\hline & & Bullock & 91 & 97 & 100 \\
\hline & & Bullock cart & 68 & 88 & 100 \\
\hline & & Tractor & - & 5 & 3 \\
\hline & & Power tiller & 1 & - & 14 \\
\hline & & Intercultivator & 1 & - & 3 \\
\hline & & Sprayer & 70 & 85 & 86 \\
\hline & & Water pump & 18 & 5 & 23 \\
\hline & & Harvesting machine & - & - & 3 \\
\hline & & Threshing machine & - & 3 & 7 \\
\hline & & Ware house & 77 & 88 & 100 \\
\hline
\end{tabular}

Source: Survey data, 2009 
Table 2. Average annual income of farm households for three levels of fragmentation

\begin{tabular}{ccccc}
\hline & & \multicolumn{3}{c}{$\%$ of income share } \\
\cline { 3 - 4 } $\begin{array}{c}\text { Degree of } \\
\text { fragmentation }\end{array}$ & $\begin{array}{c}\text { Income } \\
\text { (million kyat) }\end{array}$ & Rarm & Non-farm \\
\cline { 3 - 4 } & 1.82 & 56 & 40 & 4 \\
Low & 2.45 & 64 & 27 & 9 \\
Medium & 3.30 & 74 & 24 & 2 \\
High & & 74 & Other crops & \\
\hline
\end{tabular}

Source: Survey data, 2009

hand tools, but $3 \%$ do not possess draft animal and $12 \%$ do not possess bullock cart. For farmers in high category, all possess hand tools, draft animal and bullock cart. In terms of farm machineries, there are very small percentages that use farm machineries, only $1 \%$ use power tiller in low category, 5\% use tractor and 3\% use threshing machine in medium category. For farmers in high category $3 \%, 14 \%, 3 \%$ and $7 \%$ use tractor, power tiller, harvesting machine and threshing machine respectively.

\section{Average annual income of farm households}

The average annual incomes of farm households for three levels of land fragmentation groups are presented in Table (2). Household income is the sum of incomes of family members who earns money from several sources of work. Household incomes originate from two main sources: farm income and non-farm income. Farm incomes include incomes from rice and other crops (green gram, sesame, sunflower, maize, etc.) sold at market. Costs of production are deducted from farm income, and it includes rice for household consumption and seed for planting. Non-farm incomes are incomes obtained from non-agricultural sources such as non-farm rural wage or salary employment, non-farm rural self-employment or own business.

The average annual incomes of farm households are $1.82,2.45$, and 3.30 million kyats for low, medium and high degree of fragmentation groups respectively. Farm households' incomes for high fragmentation groups are higher than those of medium and high fragmentation groups because they possess large farm size that is the main source of income for them. Livelihoods of farm households mainly depend on farm income. Farm income accounts for 96\% (56\% of rice income and 40\% of other crops income) of total incomes of farm households for low degree of fragmentation group. The percentage share of farm income for medium fragmentation group is $91 \%$ (64\% of rice income and $27 \%$ of other crops income) of total income. For households in high fragmentation group, farm income shares 98\% (74\% of rice income and $24 \%$ of other crops income) of total income. The percent share of non-farm income is very low for all households because non-farm work is very scarce in the study area. Non-farm incomes account for $4 \%, 9 \%$ and $2 \%$ of total income for low, medium and high degree of fragmentation groups respectively.

\section{Profit margin}

Profit margin can be used to calculate the profit of a farm after paying off its total production costs. Gross profit margin illustrates how efficient management is in using its labor and resource inputs in the process of production. It is defined as net farm income expressed as a percentage of gross farm income. Net farm income is calculated by subtracting total farm expenses from gross farm income. Total farm expanse is the value of all inputs used up or expended in farm production excluding family labor. It also measures the reward to the family farm for their labor and management and the return on all the capital invested in the farm. Gross farm income is the value of the total output of the farm over some accounting period ${ }^{4}$ whether that output is sold or not. Therefore, it includes output produced which is sold; used for household consumption; used on the farm for seed; and in store at the end of accounting period.

The result of the profit margin for three levels of fragmented farms is shown in Figure (1). A higher profit margin indicates a more profitable farm that has better utilized over its resources compared with other farms. The profit margins of farms are 34\%, 28\% and 22\% for low, medium and high degree of fragmentation groups respectively. Farms with low degree of fragmentation obtained the highest profit margin because gross farm income and net farm income are high due to due to higher

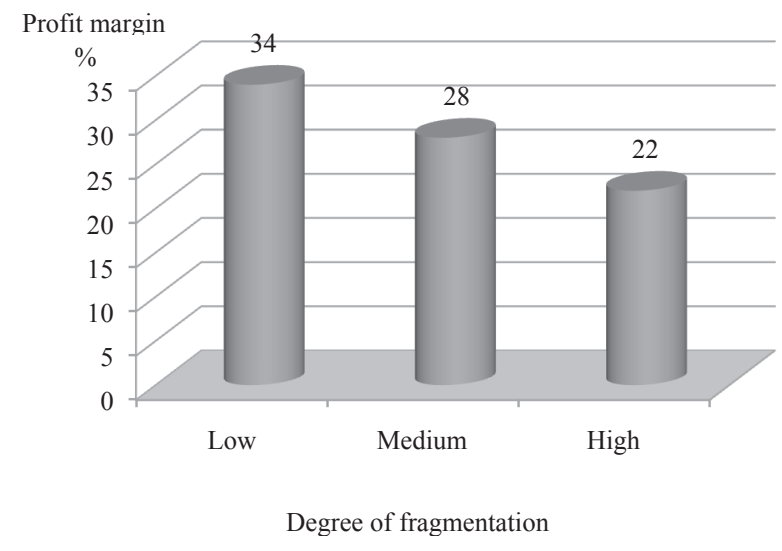

Fig. 1. Profit margin of farms for three levels of fragmentation.

\footnotetext{
${ }^{4}$ The value of total output of a farm for one season (monsoon season) was used in profit margin calculation.
} 
average rice yield per unit area. Farms for medium fragmentation group obtained profit margin lower than those of low fragmentation group, but higher than those of high fragmentation group. Farms operated with high degree of fragmentation obtained the lowest profit margin. This is because gross farm income is lower as a result of lower average rice yield per unit area.

\section{Effect of land fragmentation on input use}

Rice is the main crop which is grown once a year in monsoon season followed by other crops in the rest of the year. As rice is grown not only for consumption but also for household income, farmers have a tendency to apply more inputs to increase crop yield. Urea is the most extensively used nitrogen fertilizer in rice production. Farm yard manure is also a widely used input in rice production in the study area. The use of seed, farm yard manure, urea, compound and labor in rice production for three levels of fragmentation are presented in Table (3). The quantity of FYM and urea used vary greatly between farm groups for three levels of fragmentation. Farmers operated with high degree of fragmentation tend to use small amount of inputs (FYM and urea) than those of low degree of fragmentation, and hence yields are lower than less fragmented farms.

There is a tendency to decreasing rice yield with increasing the number of plots in a given farm size. Fig. (2) indicates a negative relationship between rice yield and number of plots. The relationship is not so clear, as

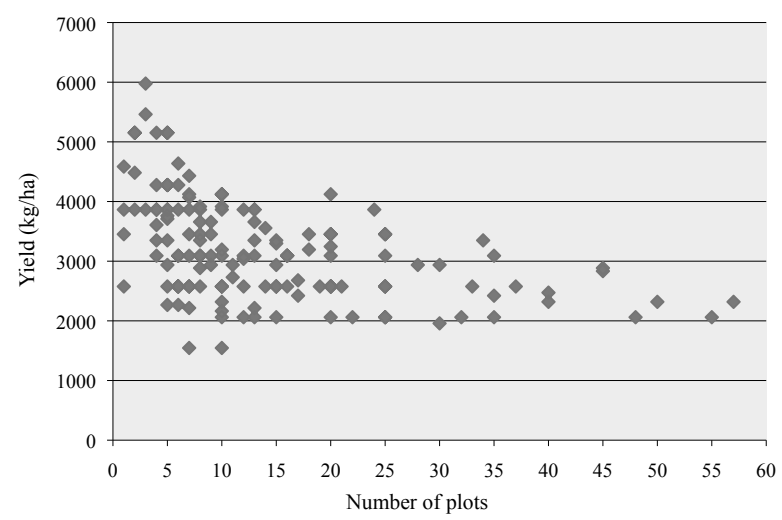

Fig. 2. Relationship between number of plots and rice yield. most plots are skewed to the left side of the figure because of the dominance of farms with small number of plots in the study area. However, figure clearly shows yield decreasing with the number of plots above 25 . This lower yield may be primarily attributed to the utilization of small amount of inputs to high fragmented farms.

\section{Effect of land fragmentation on rice productivity}

The Cobb-Douglas frontier production function was estimated using a primary data of 143 farm households in Yamethin Township. Maximum Likelihood Estimation (MLE) procedure was used to estimate the parameters of production function by using FRONTIER 4.1 computer program written by T. J. Coelli (1996).

The value of $\gamma$ (gamma) which is equal to $\sigma_{u}^{2} / \sigma^{2}$ (where $\sigma^{2}=\sigma_{\mathrm{u}}^{2}+\sigma_{\mathrm{v}}^{2}, \sigma_{\mathrm{u}}^{2}$ is the variance of one-sided error term $\mathrm{U}$ and $\sigma_{\mathrm{v}}^{2}$ is the variance of two-sided error disturbances V) are reasonable and significantly different from zero at 1\%, implying that the model disturbances capture technical inefficiency, and hence, average production function (Ordinary Least Square) is not an adequate representation of the data used in the analysis.

The estimation result of the impact of land fragmentation on rice productivity is given in Table (4). From the estimated model the coefficient of seed, urea fertilizer, land cultivated, labor are statistically significant at $1 \%$ and $5 \%$ levels respectively and have a positive effect on rice productivity. Land is the most important input in agricultural production. As a result, the estimate coefficient of land reveals that land has a significant impact on rice production and confirms that rice production can be increased through area expansion.

However, land is a constraint factor in determination of irrigated rice production. The coefficient of seed reflects that an increase in seed rate tend to increase rice yield. Farmers in the study area used improved seed varieties for their rice production. High yielding rice variety is very sensitive to fertilizers. The amount of urea fertilizer application shows a significant contribution to rice yield. The estimate coefficient of labor reflects that an increase in using family and hired labors in different farming activities may increase rice yield. Although draft animal power and farm yard manure (FYM) variables are not statistically significant, their contribution to rice yield are found to be positive.

Table 3. Input use of farms in rice production for three levels of land fragmentation

\begin{tabular}{lrcr}
\hline \multirow{2}{*}{ Input $\left(\mathrm{ha}^{-1}\right)$} & \multicolumn{3}{c}{ Degree of land fragmentation } \\
\cline { 2 - 4 } & Low & Medium & High \\
\hline Seed (kg) & 125.1 & 126.7 & 126.1 \\
Farm Yard Manure (M. ton) & 5.1 & 4.7 & 3.7 \\
Urea (kg) & 127.8 & 115.0 & 83.0 \\
Compound (N+P+K) (kg) & 48.8 & 40.2 & 35.1 \\
Total labor (man-day) & 112.1 & 115.1 & 112.9 \\
\hline Yield (kg) & 3499.0 & 2966.5 & 2594.0 \\
\hline
\end{tabular}

Source: Survey data, 2009 
Table 4. Estimation results of effects of land fragmentation on rice productivity

\begin{tabular}{|c|c|c|c|c|c|c|}
\hline Variables & OLS & Std. Err. & t-ratio & MLE & Std. Err. & t-ratio \\
\hline Constant & $2.827 * * *$ & 0.366 & 7.732 & $3.121^{* * *}$ & 0.360 & 8.664 \\
\hline Land cultivated & $0.325 * *$ & 0.170 & 1.906 & $0.362 * *$ & 0.159 & 2.278 \\
\hline Animal power & $0.180^{\mathrm{ns}}$ & 0.139 & 1.297 & $0.156^{\text {ns }}$ & 0.125 & 1.247 \\
\hline Seed & $0.346^{* * *}$ & 0.109 & 3.169 & $0.284 * * *$ & 0.099 & 2.865 \\
\hline Labor & $0.124^{*}$ & 0.066 & 1.876 & $0.135 * *$ & 0.063 & 2.151 \\
\hline Urea fertilizer & $0.119 * * *$ & 0.034 & 3.481 & $0.130 * * *$ & 0.032 & 4.033 \\
\hline Farm yard manure (FYM) & $0.014^{\mathrm{ns}}$ & 0.012 & 1.191 & $0.016^{\mathrm{ns}}$ & 0.010 & 1.507 \\
\hline Number of plots & $-0.212 * * *$ & 0.041 & -5.207 & $-0.212^{* * *}$ & 0.038 & -5.629 \\
\hline \multicolumn{7}{|l|}{ Variance parameter } \\
\hline$\sigma^{2}=\sigma_{\mathrm{u}}^{2}+\sigma_{\mathrm{v}}^{2}$ & & & & $0.092^{* * *}$ & 0.017 & 5.301 \\
\hline (Gamma) $\gamma=\sigma_{u}{ }^{2} / \sigma^{2}$ & & & & $0.894 * * *$ & 0.063 & 14.296 \\
\hline Number of respondents & 143 & & & & & \\
\hline
\end{tabular}

$*, * *$ and $* * *$ indicate statistically significant at $10 \%, 5 \%$ and $1 \%$ level respectively.

ns=not significant

Source: Own estimation from survey data 2009

The number of plots cultivated, land fragmentation indicator, significantly different from zero at $1 \%$ level and has a negative impact on rice productivity as expected. The estimated elasticity of the number of plots is -0.212 , indicates that $1 \%$ increase in the number of plots; rice output will reduce to $0.21 \%$.

It can be concluded that farms having many small plots lost space along plot boundaries, and it is difficult and time consuming for the irrigation management to all plots of land because of the plot-to-plot based traditional irrigation system in the study area. Some farms, for example, have direct access to irrigation water while others have to depend on other farms draining out water which have direct access to main irrigation canals eventually undermine agricultural productivity, efficiency and competitiveness.

Fragmentation of land plots has a farm structure that may limit the application of fertilizer inputs equally to all plots of land, and discourage farmers from efficient use of land. Farmers generally take care of and operate fertile plots of land more intensively. Farmers operating high degree of fragmentation applied small amount of material inputs than those of low degree of fragmentation although they afford to apply the necessary amount of inputs. Dijk (2003) points out that field plots located far apart or greater distances from house are generally cultivated less intensively. Separated field plots can be physically damaged by animals that lead to yield loss since most farmers are not taking care of their field plots which are quite far away from house and scattered over a wide area.

\section{CONCLUSIONS}

Data from a farm household survey of 143 farmers in four villages of in Yamethin Township were used to compare socio-economic, rice yield and farm profitability of farm households under different land fragmentation lev- els and to estimate the effects of land fragmentation on rice productivity using descriptive analysis and CobbDouglas frontier production function.

From the results of descriptive analysis, the majority of farm household heads for three levels of land fragmentation groups have primary and middle school (secondary school) education levels. Livelihoods of farm households mainly depend on farm income especially from rice and other crops. Percentage share of non-farm income is very small because non-farm employment opportunities are scarce in this area. Low fragmented farms obtained higher average rice yield and higher profit margin than medium and high fragmented farms. Higher profit margin indicates more profitable farms that has utilized over its resources more efficiently.

The result estimated from empirical model clearly reveals that land fragmentation has negative effects on rice productivity. All basic resource inputs except draft animal power and farm yard manure have a positive relationship with rice output. The estimated elasticity of land fragmentation indicates that $1 \%$ increase in the number of plots; rice output will be reduced to $0.21 \%$. This might be the result of the following factors: fragmented land plots have a farm structure that may prevent application of inputs to evenly to all plots of land and discourages farmers from efficient use of land; farms having many tiny plots lost space along plots boundaries which is directly related to the number of plots that lead to yield decrease; and unsecure scattering plots may cause yield loss because field plots are scattered over a wide area.

Some important findings emerged from this study can be useful for future policy implications. A number of policy options can be suggested for reducing land fragmentation and for promoting livelihoods of rural farmers. Therefore, attention should be paid to addressing the structural causes underlying process of land fragmentation. Tradable land use rights should be provided to farmers so that they can legally transfer agricultural land 
in the market. Regarding the number of plots within a farm, the policy reducing the number of plots should be set depending on farm size to increase productivity. Development of rural infrastructure and creation of nonfarm employment opportunities are needed to release pressure on land and enhance socio-economic status of farm households.

\section{REFERENCES}

Aigner, D. J., C. A. K. Lovell and P. Schmidt 1977 Formulation and estimation of stochastic frontier production function models. Journal of Econometrics, 6: 21-37

Bentley, J. W. 1987 Economic and ecological approaches to land fragmentation: in defense of a Much-Aligned phenomenon. Annual Review of Anthropology, 16: 31-67

Blarel, B., P. Hazell, F. Place and J. Quiggin 1992 The economics of farm fragmentation: evidence from Ghana and Rwanda. The World Bank Economic Review, 6(2): 233-254

Coelli, T. J 1996 A Guide to FRONTIER Version 4.1: A Computer Program for Stochastic Frontier Production Function Estimation. Center for Efficiency and Productivity Analysis (CEPA) Working Papers, Department of Econometrics, University of New England, Armidale, NSW 2351, Australia

Di Falco, S., I. Penov, A. Aleksiev, and T. M.v. Rensburg 2009 Agrodiversity, farm profits and land fragmentation: Evidence from Bulgaria. Land Use Policy (2009), doi.10.1016/j.landusepol.2009.10.007

Dijk, T.v. 2003 Scenarios of Central European land fragmentation. Land Use Policy, 20: 149-158

FAO/WFP 2009 Special report on FAO/WFP crop and food security assessment mission to Myanmar. Food and Agriculture Organization of the United Nations, Rome

Hung, P. V., T. G. MacAulay and S. P. Marsh 2007 The economics of land fragmentation in the north of Vietnam. The Australian Journal of Agricultural and Resource Economics, 51: 195-211

Jabarin, A. S. and F. M. Epplin 1994 Impacts of land fragmentation on the cost of producing wheat in the rain-fed region of northern Jordan. Agricultural Economics, 11: 191-196

Niroula, G. S. and G. B. Thapa 2005 Impact and causes of land fragmentation, and lessons learned from land consolidation in South Asia. Land Use Policy, 22: 358-372

Niroula, G. S and G. B. Thapa 2007 Impacts of land fragmentation on input use, crop yield and production efficiency in the mountains of Nepal. Land Degradation \& Development, 18 237-248

Ram, K. A., A. Tsunekawa, D. K. Shahad and T. Miyasaki 1999 Sub-division and land fragmentation of landholdings and their implication in desertification in the Thar desert, India Journal of Arid Environments, 41: 463-477

Soe, T. 2004 Myanmar in economic transition: Constraints and related issues affecting the agriculture sector. Asian Journal of Agriculture and Development, 1(2): 57-68

Tan, S., Heerink, N., Kruseman, G. and F. Qu 2008 Do fragmented landholdings have higher production costs? Evidence from rice farmers in Northeastern Jiangxi Province, P. R China. China Economic Review, 19: 347-358

Todorova, S. A. and D. Lulcheva 2005 Economic and social effects of land fragmentation on Bulgarian agriculture. Journal of Central European Agriculture, 6(4): 555-562

UNDP 2004. Myanmar agricultural sector review investment strategy, Volume 1 - Sector review, United Nations Development Programme (UNDP), Myanmar http://www.mm.undp.org/ UNDP_Myanmar_Publication.html

Wan, G. and E. Cheng 2001 Effects of land fragmentation and returns to scale in the Chinese farming sector. Applied Economics, 33: 183-194 